\title{
The benefits, risks, and threats of biotechnology
}

\author{
Brian Rappert
}

\begin{abstract}
This article considers how threats, risks, and benefits associated with research are defined in contemporary policy debates. Specifically, it examines what has become known as the 'dual-use potential' of life science research findings and techniques. Focus is given to the emerging dominant policy response of enacting oversight processes to weigh the risks and benefits of individual instances of research. The curiosity at the center of this article is how it is often said that any knowledge might be used for destructive ends but, in practice, it has been extremely rare that anything has even been identified as 'of concern'. This situation raises basic questions about the purposes and prospects of oversight procedures. Various proposals are advanced in reply. These include better understanding how notions of the utility of research are constructed, searching for improved methods for assessing risks and benefits, attending to factors that might affect risk-benefit calculations, pursuing alternative questions and challenging fundamental tenants in policy discussions.
\end{abstract}

$\mathrm{S}$ CIENTISTS, POLICY-MAKERS, social researchers, non-governmental organizations and others - as highlighted throughout this special issue of Science and Public Policy - have been asking whether the said potential for biotechnology to transform health and research practice might facilitate the spread of disease through inadvertent mishap or deliberate intent. If so, what needs to be done in response?

This article examines the relations between biotechnology, weapons, and regulation through examining the concept of 'biothreats'. ${ }^{1}$ Attention is given to what has become called the 'dual-use potential' of research findings and techniques (this in contrast with the dual potential for materials and equipment). This expression is used to designate the potential for findings and techniques to aid both destructive and non-destructive purposes. As such, the focus is on the end products of research rather than how it is conducted.

Brian Rappert is at the Department of Sociology and Philosophy, University of Exeter, Exeter EX4 4RJ, UK; Email: B.Rappert@ex.ac.uk; Tel: +44 1392263353.

This paper is a revised version of one given at the ESRC Biosecurity and Genomics Workshop, 13-14 November 2006, Edinburgh, and the Bioethics and Biodefense Meeting, 5 February 2007. My thanks to the participants from these two events as well as E Megan Davidson, Thomas Holohan, and Jonathan Suk.
A central curiosity under examination in this paper is how, on the one hand, it is widely said that almost any knowledge and techniques can be used for destructive purposes and how, on the other hand, in practice it has been extremely rare that anything has been identified as 'of concern'.

With regard to the former point, for instance, in the highly influential US National Research Council (NRC) report Biotechnology Research in an Age of Terrorism, Professor Gerald Fink (2003: vii) expressed concerns about the ever-present dual potential of research when he argued that "almost all biotechnology in the service of human health can be subverted for misuse by hostile individuals or nations". This report and the follow-up 2006 NRC report Globalization, Biosecurity, and the Future of the Life Sciences outlined numerous ways in which rapid developments in biotechnology and the spread of capabilities and expertise were creating ever-more realistic possibilities for modifying traditional bioweapon agents and producing new ones.

With regard to identifying specific elements that might raise security concerns, many responsive policy measures have consisted of employing existing scientific oversight mechanisms (such as peer review and institutional boards) to identify activities for scrutiny, to weigh the prospective risks and benefits of individual proposals or publications, and then to make judgments about what should be done. 
Brian Rappert is an Associate Professor of Science, Technology and Public Affairs. His long-term interest has been the examination of how choices can be and are made about the governance of technologies; this particularly in conditions of uncertainty and disagreement. His recent books include Biotechnology, Security and the Search for Limits: An Inquiry into Research and Methods (Palgrave, 2007); Technology and Security (ed., Palgrave, 2007); A Web of Prevention (ed. with Caitriona McLeish, Earthscan, 2007); and Controlling the Weapons of War: Politics, Persuasion, and the Prohibition of Inhumanity (Routledge, 2006).

For instance, in early 2003, a group of 32 science journals agreed general progress guidelines for reviewing, modifying, and perhaps rejecting manuscripts where "the potential harm of publication outweighs the potential societal benefits" (Journal Editors and Authors Group, 2003: 1464). A number of other statements have called for or codified the adoption a risk-benefit approach including the World Health Organization's Life Science Research: Opportunities and Risks for Public Health, ${ }^{2}$ the UK Biotechnology and Biological Sciences Research Council, Medical Research Council and Wellcome Trust's Managing Risks of Misuse Associated with Grant Funding Activities, 3 the American Medical Association's Guidelines to Prevent Malevolent Use of Biomedical Research, ${ }^{4}$ and the US National Science Advisory Board on Biosecurity's (NSABB) Draft Criteria for Dual Use Research of Concern. ${ }^{5}$ The last is particularly significant given that the board was set up following the recommendations of the Biotechnology Research in an Age of Terrorism report to offer advice to the federal government regarding the oversight of research.

It is worthwhile to note that the measures put in place to date have not identified many individual elements of research as 'of concern', let alone led to judgments that they should not be undertaken or somehow limited in circulation. As noted in the March 2006 meeting of NSABB, of a sample of 16,000 manuscripts submitted to the journals of the American Society for Microbiology, only three were subjected to additional biosecurity peer review and of those only one was required to be modified prior to publication. Moreover, in a 15-month period between mid-2005 and late 2006, 15 papers submitted to the journals of the Nature Publishing Group were identified as 'of concern'. None were stopped or required to make alterations (Miller, 2006).

Despite having taken dual-use considerations into account in the past in making grant decisions, prior to its 2005 statement on Managing Risks of Misuse Associated with Grant Funding Activities, the Wellcome Trust had never refused an application or sought to impose publication restrictions because of such concerns. From the time of its 2005 statement setting out a formal policy to late 2006, the trust identified three proposals as needing additional dualuse scrutiny. Of those, two were not funded for nonbiosecurity-related reasons, and the remaining one was funded after consultation with advisors (Terry, 2006). As part of the Sixth Framework Programme, the European Union (EU) set up an advisory body to review bids selected for funding for their 'dual-use' potential, which was broadly conceived as research having civilian and military utility. In 2006, 411 proposals were selected for EU funding and of those six $(1.46 \%)$ were identified as raising dual-use concerns, at least two of which were not related to the life sciences (European Commission, 2007).

As well, a US National Research Council (NRC) committee established to examine the advantages and disadvantages of restricting access to genome databases not only advocated continuing with past 'open' access practices (largely disregarding commercialization and IPR considerations), but in the 2004 report Seeking Security: Pathogens, Open Access and Genome Databases it expressed major misgivings about the possibility of identifying categories of genome data that were 'of concern'. In the cases of the publication in Nature of the sequences for remaining unsequenced parts of the 1918 Spanish flu virus (Taubenberger et al, 2005) and its artificial reconstruction published in Science (Tumpey et al, 2005), both journals and NSABB agreed the benefits of going ahead with such publications outweighed any possible risks (Rappert, 2007a).

Instead of there being a significant list of instances of problematic 'dual-use research', much of the policy focus has been with a handful of examples. This includes the undertaking and publication of the interleukin-4 gene (IL-4) mousepox experiment (Jackson et al, 2001) as well as the successful artificial chemical synthesis of poliovirus (Cello et al, 2002). For these prominent experiments, arguments that they should not have been undertaken or published because of biosecurity concerns have been exceedingly rare.

In contrast to this general pattern, it is noteworthy that the pre-project internal dual-use review conducted as part of the National Institutes of Healthfunded Southeast Regional Center of Excellence for Emerging Infections and Biodefense (SERCEB) determined 10 out of the 27 proposals were 'of concern'. This high 'hit rate' was attributed to the emphasis within SECREB on pathogens and host defenses (Davidson et al, 2007).

\section{What might be made of the paradoxical manner in which it is said that nearly any knowledge might be used for destructive ends but it has been extremely rare that any has been identified as 'of concern'?}




\section{Responses to curiosity}

What might be made of the paradoxical manner in which it is said that nearly any knowledge might be used for destructive ends but it has been extremely rare that any has been identified as ‘of concern'?

\section{Response \#1: Understand claims making process}

One starting point would be noting that assessments of the benign or malign utility of research are not determined simply by reading experimental results. Rather, much depends on how interpretations are made about the meaning of that work. Just where 'red lines', exclamation points, or question marks should be drawn because of concerns over dual-use needs to be seen as dependent on factors such as: evaluation criteria, notions of what counts as pertinent information, and proposed identified relevant contexts for consideration. Examining how criteria, data, and contexts are marshaled (and by whom) is one possible means for understanding the justification for contrasting assessments of the relevance(s) of the life sciences.

The importance of attending to the variability of scientists' accounts about the meaning of research was suggested in a classic study by Gilbert and Mulkay (1984). Based on extended interviews with biologists in the field of bioenergetics, they argued that such researchers often portrayed their work in multiple and divergent ways depending on the situation in question. The authors illustrated this variability by detailing different 'interpretative repertoires'. In writing articles, for instance, those studied overwhelmingly employed an 'empiricist repertoire'. This entailed providing highly impersonal accounts devoid of any concerns about personal preconceptions or commitments. In contrast, in more informal settings (such as interviews) this was mixed with a contingent repertoire wherein:

scientists presented their actions and beliefs as heavily dependent on speculative insights, prior intellectual commitments, personal characteristics, indescribable skills, social ties and group membership. (Gilbert and Mulkay, 1984: 56)

Rather than establishing which repertoire was correct, Gilbert and Mulkay took the variable, contextdependent status of accounts to indicate that attention should be given to how different ways of accounting for science are rhetorically organized to provide warrant for particular claims.

Building on this orientation of science claims as interpretative accomplishments, one way forward would be to compare the manner in which warrant is given to claims about the varying contribution of research to destructive and non-destructive ends. For instance, Van Aken (2006) argued that the reconstruction of the 1918 Spanish flu virus was quite risky vis-à-vis its malign use because "no virus combining high contagiousness with a comparatively high mortality rate has been readily available so far". Yet, he also argued that:

the added value of one extra strain [for peaceful applications], even one with an exceptionally high mortality rate, is limited, given that strains with varying degrees of contagiousness and pathogenicity are available and provide a wealth of research resources for comparative studies.

Just how the study of the same virus can be seen as both exceptional (for destructive ends) and ordinary (for peaceful ends) is a matter worthy of further elaboration.

Take as well debates about the merits of publishing the IL-4 mousepox experiment in the Journal of Virology (Shenk, 2003; see Rappert, 2007a). A former editor of the Journal of Virology contended that restricting IL-4 research relevant to bioweapon applications would "seriously risk disrupting" science since any attempt to do so would implicate large sways of activities. As he elaborated, the results obtained by the Australians could be "guessed at" from what was said to be "out there in the literature" (Shenk, 2003). Yet, particularly because of the prestige of the Journal of Virology, such an attribution of obviousness begs the question of why the article was published at all. Presumably, in relation to the positive scientific merit of the article, the editors determined that it made a contribution to the field.

Investigating the basis for such contrasting interpretations might well bring to the fore many implicit assumptions and ways of reasoning. Through understanding these contingent ways of reasoning, it might be possible to go further to comment on proposals for future action. For instance, in light of the general dispute about the security implications of research and the said limited novelty of the IL-4 mousepox research, the former editor of the Journal of Virology proposed that security attention be directed towards unexpected findings. Yet this is not likely to be a straightforward recommendation because of the multiple ways research is made meaningful. In general, and in contrast to many popular portrayals of science, the meaning of 'unexpected', 'new', 'unique', 'exceptional' or any other such characteristic of research is open for disagreement (Brannigan, 1981).

\section{Response \#2: Find better ways of calculating risks}

Another response would be to shore up the riskbenefit assessment methods central to procedures for evaluating research. Calls to weigh the risk and benefits of publications or experiments to date have largely been just that, general statements with little in the way of elaboration regarding what counts as risks, benefits, or how they should be weighed. 
Various statements have been made about the need for refinements of risk assessments. The report of a 2006 Royal Society-InterAcademy PanelInternational Council for Science workshop titled Science and Technology Developments Relevant to the Biological and Toxin Weapons Convention, for instance, called for improved risk assessment and management techniques (Royal Society, 2007). In relation to biothreats, Van Aken (2006) bemoaned the lack of a "systematic approach to a general riskbenefit analysis" and called for "internationally harmonized and legally binding rules" regarding the oversight of research. Holohan (2007) too has called for the use of more objective and reliable methods of risk assessment.

As part of its Prototype Protective Oversight System, individuals at the Center for International and Security Studies at the University of Maryland have suggested criteria to be incorporated into risk-benefit analysis (Harris, 2007). The criteria they offer for assessment fall under a number of categories, including biosafety issues, evaluation of research plan, public health considerations, biodefense considerations, current necessity, and potential impact.

By elaborating criteria, the Prototype Protective Oversight System goes beyond many of the current risk-benefit calls. Yet, many of its suggested criteria are likely to be the topic of considerable interpretation along the lines discussed in the previous section. For instance, answers to questions such as:

- Will the countermeasures that are expected to result from the work significantly reduce the threat posed to the agent?

- Will the proposed research contribute to new knowledge rather than primarily confirm work already done? and

- Will the proposed research advance our understanding of disease causing properties of currently existing agents?'

are likely to turn on the (varying) interpretation given to terms such as 'expected', 'new', and 'advancing'. As suggested previously, these are not matters that can simply be read from research reports. Key issues are who makes these determinations and how.

In this regard, another option is to think about the starting orientation to risks and benefits. In relation to scientific uncertainties and unknowns about the environmental costs and risks associated with topics as diverse as chemical hazards, fishing techniques, and the spread of viral diseases, the importance of a precautionary orientation has become commonplace in recent years. To be sure, just what a precautionary approach entails is varyingly defined. However, practices such as attending to ignorance, acknowledging blind spots, seeking alternative options, and incorporating 'lay' knowledge into decision-making have all been associated with it (Harremonds et al, 2002).

\section{Response \#3: Attend to conditions of assessment}

While international efforts to date might have identified few instances of research that are securityrelevant (let alone problematic), it is an open question whether that might change in the future. This is especially so given the current focus on the education of scientists and others in matters of biosecurity. In conference reports and statements, organizations such as the British Medical Association, the World Medical Association, the US National Research Council, the British Royal Society, the International Committee of the Red Cross, the InterAcademy Panel, the US NSABB, the International Council for Science as well as the states parties to the Biological and Toxin Weapons Convention have argued for greater education of those in the life sciences (see Rappert, 2007b). Again though, similar to calls to weigh risks and benefits associated with individual experiments or publications, these calls have been fairly abstract in character.

A key question for any educational activity is whether it seeks to challenge existing ways of thinking about science. As has been argued in the past with regard to vivisection, researchers can be somewhat lacking in their willingness and unaided ability to assess the downsides of their own work (Rollin, 2006).

To elaborate, many of the existing and proposed assessment procedures rely on principal investigators, peer reviewers and others to make judgments on the basis of their scientific expertise - this with little in way of explicit structured guidance or support information. When the director of the UK-based Wellcome Trust was asked in 2004 what criteria reviewers of grant applications have used to judge 'dual use' in the past, he refused to give a:

formulaic answer because I think these are all matters of judgment ... I think it is difficult to define any precise formulaic answer to that. I think they use their wisdom. ${ }^{6}$

Subsequent policy developments in the Wellcome Trust (as well as the BBRSC and Medical Research Council) embody the general spirit of relying on largely unaided scientific expertise to determine risks. Grant referees, for instance, as part of a list of issues for further consideration are asked are asked to consider "tangible risks that the research could be used for terrorist or other harmful purposes". The Wellcome Trust's 2005 Guidelines on Good Research Practice state that in relation to the risk of the misuse of research:

- In progressing their scientific investigations, researchers should actively consider any risks that their research will generate outcomes that could be misused for harmful purposes. Where such risks exist, they should seek advice and take active steps to minimise them. 
- Institutions should have in place mechanisms to ensure that risks of misuse associated with ongoing research programmes are identified and managed, and to provide advice to the researchers that they employ on these issues. ${ }^{7}$

While the second point indicates the need for advice to be given to researchers, just how this is to be done is unspecified. There are no national university educational programs being devised for public sector or other researchers in the UK that would underpin such mechanisms. In general the activities of the Wellcome Trust in relation to dual-use concerns amount to offering fairly open-ended and nonprescriptive details regarding how individuals and institutions ought to go about evaluating dual-use concerns. That is a matter for the "experts".

This stands in contrast with plans in the USA where NSABB has been tasked with advising on criteria for dual-use research, institutional governance systems for appraising research, and the make-up of mandatory biosecurity training programs for federally funded researchers.

The choices made with regard to the specific of procedures may be highly consequential in how many experiments or publications are signaled for review and the outcomes of any such procedures. For instance, questions can be asked about what guidance will be given to principal investigators in assessing risks and benefits, who else within a host institution will be required to take part in assessments, what role (if any) will be given for those with security expertise, how practicing researchers will be educated about biosecurity matters, and what mechanisms will be in place to monitor the oversight of research. Just whether, when and why assessments of research might alter from the past pattern of dual-use appraisals would be a useful topic for future empirical research. ${ }^{8}$

\section{Response \#4: Ask other questions}

Instead of merely asking how to modify the procedures of predictive risk-benefit assessments of individual elements of research, the rarity of the identification of research as 'of concern' might lead to a fundamental rethink in the way the matter of dual-use research is conceptualized. Taking as given

\section{Just whether, when and why assessments of research might alter from the past pattern of dual-use appraisals would be a useful topic for future empirical research}

for the moment the conclusion that it is extremely difficult to identify security-relevant developments, another response would be to move away from the framing of individual instances of research. Instead the cumulative developments in the life sciences would be the prime concern. So rather than asking whether particular findings taken in isolation cross some threshold, attention could be given to developments in major paths of research as a whole and, in particular, what these mean for the proliferation of enabling capabilities. As such, a more pertinent question than 'Is this finding dangerous?' is 'What is being made routine?' An exception to the otherwise absence of such overview thinking has been in the debate initiated in synthetic biology about the field's direction and implications. ${ }^{9}$

Similarly, rather than focusing on questions such as 'Should this particular experiment go ahead?' attention could be given to questions such as 'What direction of research should be funded?' (see Johnson, 1999). On the negative side, the matter of funding is particularly relevant for the USA given the massive increase in biodefense funding since 9/11 and the establishment of research institutes such as the National Biodefense Analysis and Countermeasures Center's Biological Threat Characterization Center. Much contention has surrounded whether the latter, in particular, will violate current international agreement regarding what constitutes permissible defensive activities under the Biological and Toxin Weapons Convention. On the affirmative side, consideration might also be given to directions of research that address the infectious diseases that undermine health and security worldwide, as suggested in the DNA for Peace initiative. ${ }^{10}$

\section{Response \#5: Question-starting premises}

As part of stepping back from the current framing of threats, risks and benefits, it is not only possible to ask other questions but also challenge the presumptions that underlie many current discussions. For instance, much of the existing policy debate about security in the life sciences warns against the imposition of controls because they would damage the said 'norm' of openness in scientific research that is central to the exchange of ideas and the replication of research findings (see Rappert, 2007a: Chapter 2). Yet, this sort of reaction against security restrictions stands in somewhat of a contrast to the desire to obtain commercial/intellectual property rights - a practice that, though contentious in many respects, has become further and further integrated into public sector biomedical research in recent decades.

Another way of reframing discussions would be to query the significant medical benefits so often attributed to life science research. In calling for more systematic methods for assessing risks and benefits, Van Aken (2006) argued for placing more attention on how benefits are calculated. Authors such as 
Sarewitz (1996) have gone even further to question the inevitability of the relationship between the amount of biomedical research undertaken and health improvements. Securing the latter, as he maintained, should be de-autolinked from expenditure on the former: the search for new technologies to address health problems often adds considerable costs, "obscures socioeconomic reasons for health problems [and] creates boundary to other types of action that are more effective, efficient, and equitable” (1996: 150). In other words, research is far too often seen as the best (if not the only viable) means of improving health (see as well Baker and Kaprio, 2005). The sort of rethinking suggested in this paragraph places the benefits of research in rather a less flattering light than it is often given in biosecurity discussions. In addition though, querying the likelihood that research translates into positive health benefits might well also have implications for how likely it is deemed that research can translate into destructive applications.

\section{Response \#6: Take as a sign that procedures are having an effect}

The curiosity at the center of this article need not be treated as an oddity. As suggested to the author by certain participants to the Biosecurity and Genomics Workshop from which this special issue originated, it could be taken as indicating that the procedures put in place are effective and in broad terms working. So, it could be argued that researchers have deliberately avoided submitting publications, grant applications, or experiment requests because of the procedures in place. As such, the low numbers of instances of research identified as needing scrutiny is a result of the impact of the procedures rather than the failure of them to have an impact. Depending on how one conceives of the dual-use research issue, such changes in practice may be taken as either a move to more responsible research or a sign of a damaging chill.

\section{Closing remarks}

This article has examined how threats, risks, and benefits associated with 'dual-use' life science research findings and techniques are defined in contemporary policy debates. This has been done by considering the emerging dominant response of establishing processes to weight the prospective risks and benefits of individual instances of research. The discrepancy between claims that nearly any knowledge might be used for destructive ends and experience to date with attempts to identify what is 'of concern' has been used as a springboard for questioning how threats, risks, and benefits are defined. There are significant grounds for apprehension regarding the introduction of risk-benefit assessment procedures that find little of concern.
Such assessments might either miss important developments or impose needless forms of oversight. The distinct danger for the future is that 'weighing the risks and benefits' becomes a pervasive mantra whose repetition provides (some degree of) legitimization for procedures and organizations, but little else besides.

This article has elaborated a range of possible responses to the overall state of affairs so as to move on from current policy deliberations. Each has a degree of plausibility and each likely has advantages if pursued through further investigation. While various problems and prospects have been noted with each, in closing I want to provide some overt personal remarks that have implications for future policy and research into policy.

In relation to Response \#6, if it is the case that many researchers have deliberately avoided certain actions, then this needs to be substantiated. However, given experience with risk-benefit review processes - little is identified as 'of concern' and much less affected - it seems doubtful this is the case. If researchers are restricting their actions, they are likely to be working with a mistaken view of likely consequences of reviews.

Currently within biosecurity discussions, much emphasis has been given to the second response of finding more systematic means of calculating risks. While there seems little doubt that current riskbenefit approaches could be improved, there are likely to be persistent difficulties in calculating risks of the future destructive use of research in uncertain ways by unidentified individuals. In any case, in devising any such methods, it should be borne in mind that the determination of 'risks' and 'benefits' is not a narrow technical exercise reserved for certain experts. Instead it requires the engagement of a wider range of social groups.

Because of the preliminary quality of many discussions about dual-use results and techniques as well as the often fundamentally contrasting ways of making sense of the issues at stake, Response \#1 would seem to offer a fruitful approach for investigation. Such investigations might inform dual-use educational and outreach activities. These activities are of vital importance, at least in part because of the lack of prior knowledge by practitioners or overall professional reflection on matters specifically related to dual-use results in the life sciences (Davidson et al, 2007; McLeish and Nightingale, 2005; Rappert et al, 2006).

Given the current attention (if not practical action) to education worldwide, perhaps the response in the most need of additional effort is Response \#4. The importance in attending to matters such as what research should be funded and the capacities enabled by cumulative developments is matched by the difficulty of devising forms of intervention. These are vital matters in biosecurity that raise weighty questions for those in the life sciences and beyond. 


\section{Notes}

1. Following standard conventions in intelligence studies, 'threat' is taken to be a function of capability and intent; factors often mutually determined (see Boudeau, 2007).

2. Available at <http://www.who.int/ethics/Life $\% 20$ Science $\%$ 20Research.pdf>, last accessed 20 October 2007.

3. Available at <http://www.wellcome.ac.uk/doc_wtx026594. html>, last accessed 20 October 2007.

4. Available at <http://www.biosecuritycodes.org/docs/AMA\% 20Code.pdf $>$, last accessed 20 October 2007.

5. For a description see <http://www.biosecurityboard.gov/ meetings/200603/Draft\%20Criteria\%20for\%20Identifying\% 20Dual\%20Use\%20Research-30mar.pdf>, last accessed 20 October 2007.

6. Plenary statement made at the conference titled "Do No Harm", London, the Royal Society 7 October 2004.

7. From <http://www.wellcome.ac.uk/doc_WTD002753.html>, last accessed 20 October 2007.

8. In this regard, as in the case of SERCEB rolling out educational training, the effect brought about by such endeavors for practicing scientists' and students' identification and evaluation of dual-use research as 'of concern' would be instructive to gauge. Indeed, the relative familiarity of the reviewers that were part of the SERCEB process might also be a factor in the relatively high rate at which it identified proposals as 'of concern'.

9. Including meetings such as the Venter Institute, CSIS and MIT meeting Synthetic Genomics: Risks and Benefits for Science and Society, 4 December 2006, Washington, DC.

10. DNA for Peace: Reconciling Biodevelopment and Biosecurity. Available at <http://www.utoronto.ca/jcb/home/documents/ DNA_Peace.pdf>, last accessed 20 October 2007.

\section{References}

Baker, S and J Kaprio 2005 Common susceptibility genes for cancer. British Medical Journal, 332, 15 March, 1150-1152.

Boudeau, C 2007 Producing threat assessments. In Technology and Security, ed. B Rappert. London: Palgrave.

Brannigan, A 1981 The Social Basis of Scientific Discoveries. Cambridge: Cambridge University Press.

Cello, C, A Paul and E Wimmer 2002 Chemical synthesis of poliovirus cDNA. Science, 297, 1016-1018.

Davidson, E M, R Frothingham and R Cook-Deegan 2007 Practical experiences in dual-use review. Science, 316, 8 June, 1432-1433.

European Commission 2007 Personal communication to author Reference Number: 3494133, 26 January.

Fink, G 2003 Preface. In Biotechnology Research in an Age of Terrorism, eds. National Research Council. Washington, DC NRC.

Gilbert, N and M Mulkay 1984 Opening Pandora's Box. Cambridge: Cambridge University Press.

Harremonds, P et al 2002 The Precautionary Principle. London: Earthscan.

Harris, E 2007 Dual-use biotechnology research. In $A$ Web of Prevention, eds. B Rappert and C McLeish. London: Earthscan.
Holohan, T 2007 Reflections on the role of research oversight in a web of prevention. In $A$ Web of Prevention, eds. B Rappert and $C$ McLeish. London: Earthscan.

Institute of Medicine and National Research Council 2006 Globalization, Biosecurity, and the Future of the Life Sciences. Washington, DC: IoM and NRC.

Jackson, R, A Ramsay, C Christensen, S Beaton, D Hall and I Ramshaw 2001 Expression of mouse interleukin-4 by a recombinant ectromelia virus suppresses cytolytic lymphocyte responses and overcomes genetic resistance to mousepox. Journal of Virology, 75(3), 1205-1210.

Johnson, D 1999 Reframing the question of forbidden knowledge for modern science. Science and Engineering Ethics, 5(4), 445-461.

Journal Editors and Authors Group 2003. PNAS, 100(4), 1464.

McLeish, C and P Nightingale 2005 Effective Action to Strengthen the BTWC Regime. Bradford Briefing Paper No. 17, May. Available at <http://www.brad.ac.uk/acad/sbtwc/briefing/ BP_17_2ndseries.pdf>, last accessed 20 September 2007.

Miller, L 2006 Publishing and Biosecurity. Presentation to Dual Use and Codes of Conduct Meeting, 2 December, Berlin.

NRC, National Research Council 2003 Biotechnology Research in an Age of Terrorism. Washington, DC: National Academy of Sciences.

NRC, National Research Council 2004 Seeking Security: Pathogens, Open Access and Genome Databases. Washington, DC: National Academy of Sciences.

NRC, National Research Council 2006 Globalization, Biosecurity, and the Future of the Life Sciences Washington, DC: National Academy of Sciences.

Rappert, B 2007a Biotechnology, Security and the Search for Limits. London: Palgrave.

Rappert, B 2007b Education for the life sciences. In A Web of Prevention, eds. B Rappert and C McLeish. London: Earthscan.

Rappert, B, M Chevrier and M Dando 2006 In-Depth Implementation of the BTWC. Bradford Review Conference Paper No. 18. Available at <http://www.brad.ac.uk/acad/sbtwc/>, last accessed 20 September 2007.

Rollin, B 2006 Science and Ethics. Cambridge: Cambridge University Press.

Royal Society 2007 Science and technology developments relevant to the biological and toxin weapons convention. In A Web of Prevention, eds. B Rappert and C McLeish. London: Earthscan.

Sarewitz, D 1996 Frontiers of Illusion. Philadelphia: Temple University Press.

Shenk, T 2003 Sensitive Research. Presented at Meeting on National Security and Research in the Life Sciences National Academies and the Center for Strategic and International Studies, 9 January, Washington, DC.

Taubenberger, J K, A H Reid, R M Lourens et al 2005 Characterization of the 1918 influenza virus polymerase genes. Nature, 437, 6 October, 889-893.

Terry, R 2006 Addressing Risks of Research Misuse. Presentation to Dual Use and Codes of Conduct Meeting, 2 December, Berlin

Tumpey, T M, C F Basler, P C Aguilar et al 2005 Characterization of the reconstructed 1918 Spanish influenza pandemic virus. Science, 310(5745), 7 October, 77-80.

Van Aken, J 2006 When risks outweigh benefits. EMBO Reports, 7, S10-13. Available at <http://www.nature.com/embor/journal/ v7/n1s/full/7400726.html>, last accessed 20 September 2007. 